\title{
JUICIO COLECTIVO DE DERECHOS HUMANOS EN MÉXICO
}

\author{
Collective trial on human rights in Mexico
}

Eduardo Pérez Alonso ${ }^{1}$

Sumario:

I. Introducción. II. Quejoso colectivo.III. Autoridad responsable.IV. Derechos Humanos y conceptos de violación colectiva. V. Sentencia colectiva. VI. Reparación del daño colectivo. VII. Conclusiones VIII. Bibliografía.

Resumen: Surgirá una nueva especialidad de Amparo en Derechos Humanos generada por las Reformas Constitucionales en Amparo y Derechos Humanos publicadas en México en junio de 2011. Además de tener características de una nueva materia, también exigirá un nuevo juez de perfil garantista y una nueva formación de litigante defensor de los Derechos Humanos, el reto fundamental será vincular decisiones jurisdiccionales al cumplimiento de los Derechos Humanos.

Palabras Clave: Derechos Humanos, Nuevo Proceso, Amparo, Nuevo Juez, Nuevo Abogado.

Abstract: A new specialty on Human Rights defense will emerge, generated by the Constitutional Reform published on June 2011 in Mexico. Besides having characteristics of a new subject, it will also require a new guarantee-based judge and a new litigant formation as a Human Rights defensor, the main challenge will be to link judicial decisions with Human Rights compliance.

Keywords: Human Rights, New Process, New constitutional Guarantee, New Judge, New Lawyer. Human Rights compliance.

\section{INTRODUCCIÓN}

El acceso a la justicia va más allá de la posibilidad del justiciable para presentarse ante un órgano jurisdiccional y obtener justicia; esta posibilidad es ya un gran avance; pero es solamente el comienzo del proceso jurisdiccional. Este camino de materializar "en la realidad" el cumplimiento de un derecho o el reconocimiento de una obligación es un camino con una larga lista de condiciones e implicaciones; entre otras: contar con reglas procesales claras donde se agoten las formalidades esenciales del procedimiento; se acepten y valoren las pruebas de manera adecuada, completa y correcta; donde resulte una sentencia fundada, motivada, pronta, congruente y coherente y finalmente se ejecute a plenitud la sentencia obtenida, reparando en la mayor medida posible los daños ocasionados a la víctima en el conflicto legal según sea el caso. Como lo expresa Eduardo Ferrer Mac-Gregor:

\footnotetext{
${ }^{1}$ Profesor de la División de Derecho, Política y Gobierno de la Universidad de Guanajuato. Candidato a Doctor en el programa del Doctorado Interinstitucional en Derecho.
} 
La necesidad de que los países adopten mecanismos de protección de los derechos humanos se advierte desde 1948 y debido a la influencia del amparo mexicano, en las Declaraciones Americana (art. XVII) y Universal de los Derechos del Hombre (art.1), que establecen la necesidad de que los países reconozcan en sus ordenamientos un procedimiento sencillo y breve que ampare a los particulares contra la violación de los derechos fundamentales. ${ }^{2}$

La tendencia internacional en materia de la defensa de los derechos humanos es garantizar su acceso a la justicia a fin de tutelar de manera efectiva a quien sea vulnerado en sus libertades y derechos fundamentales. Se pretende detener o por lo menos llegar a disminuir de alguna manera los efectos negativos de la sociedad globalizada contemporánea. Están en riesgo las diferencias que definen las identidades culturales de las sociedades, de las comunidades y de las personas a manos del ejercicio discriminatorio del poder global, que legaliza la desigualdad, que hace permanente que pocos tengan las mayores prerrogativas y muchos carezcan de lo más elemental.

México, país de tradición civil jurídica positivista construyó su sistema legal bajo una concepción liberal individualista, que estableció entre otros paradigmas jurídicos, la añeja fórmula otero como coloquialmente se le llama al principio de agravio personal y directo, ${ }^{3}$ que reconoce legitimación y aplica el derecho en resoluciones de ley de amparo, solo a quien demuestre un agravio personal y directo, limitando la legitimación ad causam a los que acrediten un interés jurídico; marginando de la aplicación de la ley a los que tienen un interés legítimo que hacer valer y que no cuentan con los elementos para acreditar su personalidad y su interés jurídico por no estar organizados o reconocidos jurídicamente.

México está enfrentando sus paradigmas democráticos y constitucionales mediante reformas de gran calado a su sistema jurídico y en general a todo el sistema constitucional mediante tres ejes que consisten:En el reconocimiento del interés legítimo, en la declaración general de inconstitucionalidad y en el establecimientos del bloque de constitucionalidad que reconoce los derechos humanos establecidos en la Constitución y en los Tratados Internacionales firmados por el Estado Mexicano.

En el mes de junio del año de 2011, se publicaron en el Diario Oficial de la Federación de México las Reformas Constitucionales en materia de Derechos Humanos y en Amparo. La reforma en Derechos Humanos expresa en el artículo $1^{\circ}$ Constitucional en sus tres primeros párrafos:

En los Estados Unidos Mexicanos todas las personas gozarán de los derechos humanos reconocidos en esta Constitución y en los tratados internacionales de los que el Estado Mexicano sea parte, así como de las garantías para su protección, cuyo ejercicio no podrá restringirse ni suspenderse, salvo en los casos y bajo las condiciones que esta Constitución establece.

\footnotetext{
${ }^{2}$ Ferrer Mac-Gregor, Eduardo, Estudios Constitucionales, Revista Semestral del Centro de Estudios Constitucionales, Universidad de Talca, Facultad de Ciencias Jurídicas y Sociales, Centro de Estudios Constitucionales. 2006. p.16.

3 Martí, Capitanachi, L. "La Fórmula Otero" en Revista Letras Jurídicas, de los Investigadores del Instituto de Investigaciones Jurídicas de la Universidad de Veracruzana, no. 2 Xalapa 200o, pp.173-19o.
} 
Las normas relativas a los derechos humanos se interpretarán de conformidad con esta Constitución y con los tratados internacionales de la materia favoreciendo en todo tiempo a las personas la protección más amplia.

Todas las autoridades, en el ámbito de sus competencias, tienen la obligación de promover, respetar, proteger y garantizar los derechos humanos de conformidad con los principios de universalidad, interdependencia, indivisibilidad y progresividad. En consecuencia, el Estado deberá prevenir, investigar, sancionar y reparar las violaciones a los derechos humanos, en los términos que establezca la ley. ${ }^{4}$

La reforma constitucional en amparo está contenida en los siguientes artículos:

Artículo 103. Los Tribunales de la Federación resolverán toda controversia que se suscite:

I. Por normas generales, actos u omisiones de la autoridad que violen los derechos humanos reconocidos y las garantías otorgadas para su protección por esta Constitución, así como por los tratados internacionales de los que el Estado Mexicano sea parte;

II. Por normas generales o actos de la autoridad federal que vulneren o restrinjan la soberanía de los estados o la esfera de competencia del Distrito Federal, y

III. Por normas generales o actos de las autoridades de los Estados o del Distrito Federal que invadan la esfera de competencia de autoridades federales.

Artículo 107. Las controversias de que habla el artículo 103 de esta Constitución, con excepción de aquellas en materia electoral, se sujetarán a los procedimientos que determine la ley reglamentaria, de acuerdo con las bases siguientes:

I. El juicio de amparo se seguirá siempre a instancia de parte agraviada, teniendo tal carácter quien aduce ser titular de un derecho o de un interés legítimo individual o colectivo, siempre que alegue que el acto reclamado viola los derechos reconocidos por esta Constitución y con ello se afecte su esfera jurídica, ya sea de manera directa o en virtud de su especial situación frente al orden jurídico.Tratándose de actos o resoluciones provenientes de tribunales judiciales, administrativos o del trabajo, el quejoso deberá aducir ser titular de un derecho subjetivo que se afecte de manera personal y directa. ${ }^{5}$

Estas reformas deben ser entendidas en una estructura jurídica que rompe con toda la tradición positivista e individualista del ejercicio litigioso en México y aunadas a los criterios de la Décima Época de la Suprema Corte de Justicia de la Nación publicadas en el mes de octubre de 2011 serán letra de ley y criterios de interpretación vigentes y de aplicación conjunta. La nueva Ley de Amparo se modificó y publicó el 2 de abril de 2013 adaptándose a las nuevas instituciones garantistas plasmadas en las reformas constitucionales citadas anteriormente a y en todo caso su interpretación operativa deberá respetar la motivación y fundamentos de reconocer jurídicamente a los derechos humanos y garantizarlos para su

\footnotetext{
${ }^{4}$ Diario Oficial de la Federación. Decreto por el cual se modifica la denominación del Capítulo I de Título Primero y reforma diversos artículos de la Constitución Política de los Estados Unidos Mexicanos. México. 10 de junio de 2011.

5 Diario Oficial de la Federación. Decreto por el cual se reforman, adicionan y derogan diversas 94, 103,104 y 107 de la Constitución Política de los Estados Unidos Mexicanos. México. 6 de junio de 2011.
} 
debido cumplimiento, que son los aspectos torales de estas modificaciones constitucionales de gran calado.

Las tres columnas de la reforma constitucional en derechos humanos y amparo se establecen en los siguientes los artículos: $1^{\circ}$ Constitucional, que cimenta el bloque de constitucionalidad; 103 Constitucional, que determina la competencia federal y la materia para actos u omisiones que vulneren derechos reconocidos en la Constitución y en tratados internacionales y el 107 Constitucional, que reconoce el interés legítimo individual o colectivo. Estas nuevas figuras constitucionales hacen en su conjunto un poderoso motor de cambio de dimensiones aún desconocidas y que observo como una puerta con tres grandes entradas enmarcadas por el reconocimiento de los derechos humanos a nivel constitucional, el acceso a la justicia aduciendo el interés legítimo, ya sea individual o colectivo y la declaratoria general de inconstitucionalidad con efectos erga omnes. Estos cambios generan un nuevo orden constitucional donde el foro tendrá la tarea de presentar juicios de derechos humanos y los jueces deberán resolver dentro del marco de protección estos derechos reconocidos en la Constitución y en los tratados internacionales firmados por el estado mexicano.

Entrar por esta puerta de tres columnas, implica una revolución jurídica que espero que lleve a México a una revolución cultural donde las personas hagan valer sus derechos de manera colectiva, lo que es una necesidad impostergable dada la enorme complejidad de los problemas por los que nuestro país está pasando y que requieren soluciones de fondo, de cambio de rumbo y de oportunidades democráticas para todos los mexicanos, donde un acceso democrático a la justicia en México, sea una realidad para todos las personas a fin de consolidar el proyecto de nación y nosea el estado de fallido en que pudiéramos convertirnos.

\section{QUEJOSO COLECTIVO}

La adopción de la institución del interés legítimo como institución constitucional para promover el juicio de derechos humanos rompe el rígido concepto del interés jurídico reservado a los titulares de derechos subjetivos reconocidos en norma positiva y que ha servido en México para dar justicia solo a los propietarios de los derechos y establece la concepción de un quejoso colectivo como parte en el juicio de amparo al reconocerle interés legítimo colectivo. Con esto se genera en México el juicio de derechos colectivos en la vía de amparo que ahora tienesu reglamentación en la nueva ley de amparo.

Los presupuestos procesales del amparo colectivo son: competencia jurisdiccional en tribunales federales, materia relativa al bloque de derechos humanos reconocidos en la constitución y en tratados internacionales, demanda interpuesta por un quejoso aduzca ser titular de un interés legítimo colectivo atacando un acto reclamado por acción u omisión que vulnere la esfera jurídica del quejoso colectivo de manera directa o en virtud de una especial situación frente al orden jurídico.

El artículo 107 fracción I de la reforma constitucional de amparo deja a interpretación que se entiende por "interés legítimo"y una "especial situación frente al orden jurídico", lo cual dará inicio a un debate doctrinal y jurisprudencial en los próximos años en el foro mexicano. Para desentrañar el alcance de este concepto debemos leer en primera instancia la obra del Ministro Arturo Zaldívar Lelo de Larrea, uno de los principales autores de las reformas de amparo, quien establece que el interés legítimo y la afectación tienen las siguientes características: 
Los titulares tienen un interés propio distinto del de cualquier gobernado, consistente en que los poderes públicos actúen de acuerdo con el ordenamiento cuando con motivo de la persecución de fines de carácter general incidan en el ámbito de ese interés propio, se trata de un interés cualificado, actual y real, no potencial ni hipotético; en suma un interés jurídicamente relevante, en donde, debe haber una afectación a la esfera jurídica en sentido amplio, ya sea económica, profesional o de cualquier índole, que de prosperar la acción o la anulación se traduce en un beneficios jurídico para el accionante. ${ }^{6}$

Por su parte Eduardo Ferrer Mac-Gregor estima que el interés legítimo se da en cualquier persona física o jurídica que estime violentado sus derechos fundamentales. ${ }^{7}$

Estoy de acuerdo con estas ideas y considero que habrá que añadir que el interés legítimo además de ser cualificado, actual, real y que surge de una especial situación frente al orden jurídico, que viole derechos fundamentales; que es un interés compartido, grupal y multidimensional. Lo anterior, me parece ya que el interés legítimo inicia con la persona con dimensión social que se agremia porque comparte derechos desde su grupo de referencia, hacia su comunidad, su sociedad y el mundo global. Si decimos que hay interés legítimo debemos aceptar que no puede limitarse de manera rígida y que puede llegar a ser compartido, aún con la comunidad internacional.

La nueva Ley de Amparo publicada el 2 de Abril del 20138 se genera sobre la estructura de la reforma constitucional en amparo y admite la posibilidad de promover el amparo mediante el reconocimiento del interés legítimo y conjuntamente por dos o más quejosos cuando resientan una afectación común en sus derechos o intereses, aún en el supuesto de que dicha afectación derive de actos distintos, si éstos les causan un perjuicio análogo y provienen de las mismas autoridades.Como lo expresa Murillo Karam en la iniciativa presentada en la Cámara de Senadores del H. Congreso de la Unión:

Artículo $5^{\circ}$. Son partes en el juicio de amparo: I. El quejoso, teniendo tal carácter quien aduce ser titular de un derecho o de un interés legítimo individual o colectivo, siempre que alegue que la norma, acto u omisión reclamados violan los derechos previstos en el artículo primero de la presente ley y con ello se afecte su esfera jurídica, ya sea de manera directa o en virtud de su especial situación frente al orden jurídico.

El juicio de amparo podrá promoverse conjuntamente por dos o más quejosos cuando resientan una afectación común en sus derechos o intereses, aún en el supuesto de que dicha afectación derive de actos distintos, si éstos les causan un perjuicio análogo y provienen de las mismas autoridades. Tratándose de actos o resoluciones provenientes de tribunales

\footnotetext{
${ }^{6}$ Zaldivar, Lelo de Larrea, A. Hacia una nueva Ley de Amparo. México. UNAM, Instituto de Investigaciones Jurídicas, 2002. p. 63

7 Ferrer Mac-Gregor, Eduardo. Estudios Constitucionales. Revista Semestral del Centro de Estudios Constitucionales. Chile. Universidad de Talca, Facultad de Ciencias Jurídicas y Sociales, Centro de Estudios Constitucionales, 2006. p. 25

${ }^{8}$ Diario Oficial de la Federación. Ley de Amparo, Reglamentaria de los artículos 103 y 107 de la Constitución Política de los Estados Unidos Mexicanos.2 de abril de 2013.
} 
judiciales, administrativos o del trabajo, el quejoso deberá aducir ser titular de un derecho subjetivo que se afecte de manera personal y directa. ${ }^{9}$

El texto de la iniciativa original fue modificado en el dictamen final, de la nueva ley de amparo, sumando algunas especificaciones al interés legítimo. Las cuales transcribo a continuación:

Artículo 5o. Fracción ISon partes en el juicio de amparo:

El quejoso, teniendo tal carácter quien aduce ser titular de un derecho subjetivo o de un interés legítimo individual o colectivo, siempre que alegue que la norma, acto u omisión reclamados violan los derechos previstos en el artículo 1o de la presente Ley y con ello se produzca una afectación real y actual a su esfera jurídica, ya sea de manera directa o en virtud de su especial situación frente al orden jurídico

El interés simple, en ningún caso, podrá invocarse como interés legítimo. La autoridad pública no podrá invocar interés legítimo.

El juicio de amparo podrá promoverse conjuntamente por dos o más quejosos cuando resienta una afectación común en sus derechos o intereses, aun en el supuesto de que dicha afectación derive de actos distintos, si éstos les causan un perjuicio análogo y provienen de las mismas autoridades. Tratándose de actos o resoluciones provenientes de tribunales judiciales, administrativos, agrarios o del trabajo, el quejoso deberá aducir ser titular de un derecho subjetivo que se afecte de manera personal y directa; La víctima u ofendido del delito podrán tener el carácter de quejosos en los términos de esta Ley. ${ }^{10}$

En este nuevo texto de la ley de amparo observo que de manera expresa se vincula la materia de amparo a los extremos del artículo $1^{\circ}$ de esta misma ley, como ya se había comentado y con esto se tutela contra normas generales, actos u omisiones que violen derechos humanos y garantías otorgadas por la constitución y los tratados internacionales. Esto confirma a mi juicio un bloque de constitucional o un corpus iuris en derechos humanos, por lo que considero que la ley reglamentaria respeta a cabalidad la reforma constitucional de amparo en cuanto al catálogo o conjunto de derechos que pueden ser invocados en el nuevo amparo mexicano.

La variante que se detecta es que para aducir ser titular de un interés individual o colectivo se establece que tiene que producir una afectación real y actual a su esfera jurídica ya sea de manera directa o en virtud de una situación especial frente al orden jurídico. Considero que el expresar una afectación de tales características a su esfera jurídica, puede generar una interpretación de naturaleza individualizada ya que por tradición la esfera jurídica está muy vinculada a los derechos de la personalidad individual entendida como un conjunto

\footnotetext{
${ }^{9}$ Murillo Karam, J. Cámara de Senadores de diversos Grupos Parlamentarios. Proyecto de decreto por el que se expide la Ley de Amparo reglamentaria de los artículo 103 y 107 Constitucionales y se reforman y adicionan diversas disposiciones de la Ley Orgánica del Poder Judicial de la Federación, de la Ley Reglamentaria de las Fracciones I y II del artículo 105 de la Constitución Política de los Estados Unidos Mexicanos, de la Ley Orgánica de la Administración Pública Federal, de la Ley Orgánica del Congreso General de los Estados Unidos Mexicanos, y de la Ley Orgánica de la Procuraduría General de la República. México 2011.

${ }^{10}$ Diario Oficial de la Federación. Ley De Amparo, Reglamentaria De Los Artículos 103 y 107 De La Constitución Política De Los Estados Unidos Mexicanos, Articulo 5 , 2 de abril del 2013.
} 
de derechos públicos subjetivos. Aprecio por venir un intenso debatepara definir lo que se entiende por una esfera jurídica colectiva y su afectación real y actual.

Este mismo texto del artículo $5^{\circ}$ establece un extremo para descalificar el interés legítimo y su posible apariencia de interés simple, expresando que el interés simple no puede entenderse como interés legítimo. Y con esto confirmo el que va a ser materia de mucha discusión cuando estemos en presencia de un mero interés simple o en presencia de un interés colectivo de carácter difuso. Se van a presentar dos posturas al menos de esta cuestión: las que suman demasiados requisitos para encontrar un interés legítimo colectivo o las que van a identificar de manera muy fácil el que un interés legítimo colectivo será un interés simple.

Un estudio sobre el interés legítimo como elemento de acción de amparo lo encontramos por los autores Ulises Schmill Ordoñez y Carlos de Silva Nava, quienes establecen los siguientes elementos para la existencia de un interés legítimo:

1. Existencia de una norma que establece o tutela algún interés difuso en beneficio de una colectividad determinada.

2. Afectación de ese interés difuso en perjuicio de esa colectividad por la ley o acto que se reclama, y

3. Pertenencia del quejoso a dicha colectividad. ${ }^{11}$

Para Jean Claude Tron Petit: En consecuencia para que un pretendido interés no sea reputado como simple deben concurrir los siguientes requisitos:

1. Especial posición cualificada de la persona o colectivo recurrente;

2. Círculo de intereses individual o colectivo afectado, distinto de uno general o universal;

3. Un interés propio, distinto del de cualquier otra persona;

4. Conveniencia o provecho específicos de ser acogida la pretensión;

5. Utilidad real, específica y diferenciada para el recurrente o interesado, es insuficiente un agravio vago o impreciso;

6. No afectación a un derecho subjetivo ni a la esfera jurídica del particular o colectivo; y,

7. El orden jurídico debe estipular un reconocimiento mayor que formular una simple denuncia, estableciendo un poder para exigir algo específico a favor del interés particular o colectivo lesionado. ${ }^{12}$

A mi juicio, la Décima Época de la corte y su nuevo espíritu constitucional dirigido a la tutela de derechos humanos tendrá la tarea de clarificar lo que llegará a ser para la ley de amparo el interés legítimo, ya que esta institución jurídica será discutida permanentemente en la

\footnotetext{
${ }^{11}$ Schmill Ordoñez, Ulises y De Silva Nava, Carlos. El Interés Legítimo como Elemento de la Acción de Amparo. www.sitios.scjn.gob.mx/instituto/sites/3 marzo de 2013

${ }^{12}$ Tront Petit, Jean Claude.¿Qué hay de interés legítimo? http://www.jeancluadetronp.com 15 de marzo de 2013. 
diversidad de casos que se presenten. Transcribo una tesis de la primera sala de esta Décima Época, que expone:

INTERÉS LEGÍTIMO EN EL AMPARO. SU DIFERENCIA CON EL INTERÉS SIMPLE. La reforma al artículo 107 constitucional, publicada en el Diario Oficial de la Federación el 6 de junio de 2011, además de que sustituyó el concepto de interés jurídico por el de interés legítimo, abrió las posibilidades para acudir al juicio de amparo. No obstante lo anterior, dicha reforma no puede traducirse en una apertura absoluta para que por cualquier motivo se acuda al juicio de amparo, ya que el Constituyente Permanente introdujo un concepto jurídico mediante el cual se exige al quejoso que demuestre algo más que un interés simple o jurídicamente irrelevante, entendido éste como el que puede tener cualquier persona por alguna acción u omisión del Estado pero que, en caso de satisfacerse, no se traducirá en un beneficio personal para el interesado, pues no supone afectación a su esfera jurídica en algún sentido. En cambio, el interés legítimo se define como aquel interés personal, individual o colectivo, cualificado, actual, real y jurídicamente relevante, que puede traducirse, en caso de concederse el amparo, en un beneficio jurídico en favor del quejoso derivado de una afectación a su esfera jurídica en sentido amplio, que puede ser de índole económica, profesional, de salud pública, o de cualquier otra. Consecuentemente, cuando el quejoso acredita únicamente el interés simple, mas no el legítimo, se actualiza la causal de improcedencia prevista en el artículo 73, fracción XVIII, de la Ley de Amparo, en relación con el numeral 107, fracción I, de la Constitución Política de los Estados Unidos Mexicanos. ${ }^{13}$

Mi punto de vista en torno al interés legítimo en la nueva Ley de Amparo es que no debemos caer en la rigidez y acumulación de requisitos para acreditarlo, ya que este tipo de interés no es un punto intermedio entre el interés jurídico y el interés simple. Recordemos que esta institución proviene de una reforma constitucional y por lo tanto la Ley de Amparo debe interpretarse en función de su reforma constitucional que no estableció requisitos para acreditar el interés legítimo. Una esfera jurídica colectiva no es la suma de esferas jurídicas individuales, ni la suma de intereses públicos subjetivos de individuos en litisconsorcio activo. La esfera jurídica colectiva se integra por un grupo al que se le vulneran derechos e intereses comunes y su reconocimiento supera el tradicional acreditamiento de la personalidad jurídica y el interés jurídico. Habrá casos donde ya exista una afectación a un bien colectivo y aún no se pueda demostrar la afectación en los individuos del grupo. Por ejemplo: Si tenemos la afectación del agua de un río por desechos industriales, agua que sirve para regar sembradíos de la comunidad aledaña; no podemos esperar a que se presenten las enfermedades en los individuos de la comunidad para acreditar el interés legítimo. Considero que en esta materia de verdad se requiere un análisis que se aparte de la clásica identificación del derecho público subjetivo de carácter individualizado y se logre una apreciación de los derechos e intereses colectivos.

Una vez salvado el requisito del interés legítimo, se pueden visualizar tres opciones para la legitimación en proceso: Una cuando un quejoso persona física haga valer intereses legítimos colectivos, una segunda opción puede darse cuando dos o más quejosos personas

\footnotetext{
${ }^{13}$ Tesis aislada XLIII/2013 (10 $10^{\text {a }} 85$ de la Primera Sala de la SCJN. INTERÉS LEGÍTIMO EN EL AMPARO. SU DIFERENCIA CON EL INTERÉS SIMPLE.
} 
físicas hagan valer intereses legítimos colectivos y una tercera opción cuando una o varias asociaciones civiles, hagan valer intereses legítimos colectivos.

Para el caso de un quejoso persona física haga valer intereses legítimos colectivos, es evidente que puede hacerlo y que este es el espíritu de esta nueva legislación. Para el caso de dos o más quejosos personas físicas o personas morales, debe prevalecer el mismo criterio para aceptar la legitimación activa cuando se aduce ser titular de un interés legítimo. Considero que es correcto que la personalidad en el proceso conserve amplitud, sin restricciones, sin condiciones, salvo la de aducir un interés legítimo colectivo.

La posibilidad de que varios quejosos acudan al juicio de derechos humanos, darán la oportunidad de acumular los procedimientos o que la autoridad responsable alegue litispendencia. Considero que debe prevalecer y que estas figuras no detengan el procedimiento haciendo prevalecer el criterio de que el procedimiento de amparo debe ser sencillo, ágil y proteccionista.

Cabe aclarar que el amparo colectivo se endereza contra actos de autoridad responsable de un acto reclamado de acción u omisión que viole derechos humanos de fuente constitucional e internacional, con lo que la esfera competencial de este juicio se traduce en materia administrativa o de ejercicio de la función pública. Habrá que distinguir entre este juicio de derechos colectivos y las acciones colectivas, en el contexto mexicano. En estos momentos ya existe en México una reforma constitucional y legal en matera de acciones colectivas que tiene las siguientes características básicas: restringida a la materias de consumo de bienes y servicios y la materia de protección al medio ambiente, ejerciendo acciones por derechos difusos, derechos colectivos y derechos individuales homogéneos, y consiste en la adición de un párrafo tercero al artículo 17 Constitucional ${ }^{14} \mathrm{y}$ en un conjunto reformas y adiciones el Código Federal de Procedimientos Civiles, el Código Civil Federal, la Ley Federal de Competencia Económica, la Ley Federal de Protección al Consumidor, la Ley Orgánica del Poder Judicial de la Federación, la Ley General del Equilibrio Ecológico y la Protección al Ambiente como se publicó en el Diario Oficial de la Federación : Artículo 578: La defensa y protección de los derechos e intereses colectivos será ejercido ante los Tribunales de la Federación con las modalidades que señala este Título, y solo podrán promoverse en materia de relaciones de consumo de bienes o servicios públicos o privados o medio ambiente. ${ }^{15}$

De la presencia de estos dos órdenes normativos de procedimientos colectivos considero que en lo futuro se debe integrar un sistema que resuelva lagunas y antinomias que se puedan presentar al momento de que operen los dos sistemas. Es un grave problema que se confunda derechos y garantías y que al momento de legislar se incurra en contradicciones entre normas. Sobre este tema Luigi Ferrajoli, considera a las antinomias como inevitables16cuya solución requiere de una redefinición adecuada para resolver en el intérprete los problemas de aplicación provocados por le imperfección de la norma.17

\footnotetext{
${ }^{14}$ Constitucion Politica de los Estados Unidos Mexicanos. La reforma constitucional dice: El Congreso de la Unión expedirá las leyes que regulen las acciones colectivas. Tales leyes determinarán las materias de aplicación, los procedimientos judiciales y los mecanismos de reparación de daño. Los jueces federales conocerán de forma exclusiva sobre estos procedimientos y mecanismos

${ }^{15}$ Diario Oficial de la Federación. Decreto que reforma y adiciona el Código Federal de Procedimientos Civiles, la Ley Federal de Protección al Consumidor, de la Ley Orgánica del Poder Judicial de la Federación, de la Ley General del Equilibrio Ecológico y la Protección al Medio Ambiente y de la Ley de Protección y Defensa al Usuario de Servicios Financieros. México. 30 de agosto de 2011. 2011.

${ }^{16}$ Ferrajoli, Luigi. Principia Iuris. Tomo 1.Teoría del derecho. Fontamara, Madrid, 2011, p. 644

${ }^{17}$ Idem., p. 645
} 


\section{AUTORIDAD RESPONSABLE}

Una de las grandes innovaciones en la nueva Ley de Amparo es la modificación del concepto de autoridad responsable, dando trato de sujeto pasivo en la causa a los particulares que desempeñen actividades equivalentes a las de una autoridad. Considero un avance positivo esta amplitud ya que cada vez más particulares desempeñan actividades propias de Estado mediante concesión. El artículo 5 fracción II de la nueva Ley de Amparo, expone:

La autoridad responsable, teniendo tal carácter, con independencia de su naturaleza formal, la que dicta, ordena, ejecuta o trata de ejecutar el acto que crea, modifica o extingue situaciones jurídicas en forma unilateral y obligatoria; u omita el acto que de realizarse crearía, modificaría o extinguiría dichas situaciones jurídicas.

Para los efectos de esta Ley, los particulares tendrán la calidad de autoridad responsable cuando realicen actos equivalentes a los de autoridad, que afecten derechos en los términos de esta fracción, y cuyas funciones estén determinadas por una norma general. ${ }^{18}$

\section{DERECHOS HUMANOS Y CONCEPTOS DE VIOLACIÓN COLECTIVA}

Se observa que la mecánica de protección que se realizó en México consistió en constitucionalizar los derechos humanos, dándoles el carácter de derechos fundamentales. Con este reconocimiento, la discusión que entendía diferencias entre derechos humanos y derechos fundamentales queda salvada y se formula un sistema de ius - naturalismo positivado, que eleva a rango constitucional un catálogo amplio de derechos humanos. Miguel Carbonell, hace un estudio profundo de la conceptualización de los derechos fundamentales entendiéndolos como aquellos que están consagrados en la Constitución. ${ }^{19}$

Este reconociendo puede ser entendido como un límite al poder del estado, por una esfera que funciona como un jusgentium internacional. En esta tendencia se pronuncia el autor Antonio Augusto Cancado Trindade al establecer el nuevo iusgentium, en el Caso Olmedo Bustos y Otros versus Chile, en la conclusión décimo tercera: "En este inicio del siglo $\mathrm{XXI}$, se requiere una reconstrucción y renovación del derecho de gentes, a partir de un enfoque necesariamente antropocéntrico, y no más estatocéntrico como en el pasado, dada la identidad del objetivo último tanto del derecho internacional como del derecho interno en cuanto a la salvaguarda plena de los derechos de la persona humana. ${ }^{20}$

El bloque de constitucionalidad o corpus iuris en derechos fundamentales establecido en la Constitución mexicana en su artículo $1^{\circ}$ presenta las siguientes características:

1. Un Bloque de Derechos Humanos Constitucionales e Internacionales: En los Estados Unidos Mexicanos todas las personas gozarán de los derechos humanos reconocidos en esta Constitución y en los tratados internacionales de los que el Estado Mexicano sea parte, así como de las garantías para su protección.

2. Una Interpretación Conforme y Proteccionista: Las normas relativas a los derechos humanos se interpretarán de conformidad con esta Constitución y con los tratados in-

\footnotetext{
${ }^{18}$ Diario Oficial de la Federación. Ley De Amparo, Reglamentaria De Los Artículos 103 Y 107 de la Constitución Política De Los Estados Unidos Mexicanos. Articulo 5․ 2 de abril del 2013.

${ }^{19}$ Carbonell, Miguel, Los derechos fundamentales en México. Porrúa, México, 2011, p.1-14.

${ }^{20}$ Cancado, Antonio, Derecho Internacional de los Derechos Humanos, Porrúa, México, 2007, p. 240.
} 
ternacionales de la materia favoreciendo en todo tiempo a las personas la protección más amplia.

3. Un Amplio Control de Convencionalidad: Todas las autoridades, en el ámbito de sus competencias, tienen la obligación de promover, respetar, proteger y garantizar los derechos humanos de conformidad con los principios de universalidad, interdependencia, indivisibilidad y progresividad.

4. Una Obligación Re-constitutiva de la Persona Social y del Estado Social: El Estado deberá prevenir, investigar, sancionar y reparar las violaciones a los derechos humanos, en los términos que establezca la ley.

Con lo anterior, afirmo que la actividad garantista del Juez en México será una de las características principales de esta nueva etapa, que inició plenamente el 4 de octubre de 2011 con la entrada en vigor de la reforma Constitucional de Amparo, la publicación del acuerdo de la Décima Época de la Suprema Corte de Justicia de la Nación y la publicación en el Diario Oficial de la Federación del Caso Rosendo Radilla, La actuación de los jueces mexicanos será determinante para llegar a buen puerto en estas reformas, por lo que su capacitación constante, su responsabilidad social y su Interpretación conforme y en control de convencionalidad, forjarán un nuevo rostro del poder judicial en México.

Para aplicar la interpretación conforme y el principio de convencionalidad en el contexto mexicano, figuras fundamentales de estas reformas constitucionales de amparo y de derechos humanos, debemos atender a los criterios para operar estos principios establecidos en la publicación del Caso Radilla en el Diario Oficial de la Federación del 4 de octubre de 2011 que establece:

1. Las sentencias de la Corte Interamericana de los Derechos Humanos son obligatorias para el Estado Mexicano.

2. La jurisprudencia del Corte Interamericana de los Derechos Humanos se constituye como un criterio orientador en la resolución de los casos correspondientes.

3. Se establece el control de convencionalidad que consiste en que los jueces deben revisar de oficio que las disposiciones que apliquen no violenten la constitución ni lo tratados internacionales, por lo que los jueces del Estado Mexicano están obligados a implicar las normas contrarias a la Constitución y a los tratados internacionales en materia de derechos humanos. $^{21}$

Para el foro la formulación de conceptos de violación colectiva en derechos humanos y en derechos de fuente internacional, será una responsabilidad social sin precedente para los abogados litigantes, que requiere capacitación a cargo de las escuelas y facultades de derechos en el país y que a su vez se debe traducir en la actualización de los planes de estudio relativas a este nuevo orden constitucional y nueva dimensión litigiosa de la actividad los abogados postulantes. Ya que sin casos, no puede operar el sistema que las reformas constitucionales contemplan.

\footnotetext{
${ }^{21}$ Diario Oficial de la Federación. Caso Radilla Pacheco. 9 de Febrero del 2010.
} 


\section{SENTENCIA COLECTIVA}

Si bien es cierto que con el reconocimiento del interés legítimo para promover el juicio de derechos humanos se abre la puerta de manera de amplia en cuanto al acceso a la justicia se refiere, persiste la relatividad de las sentencias en cuanto a los efectos de la sentencia que conceda el amparo, y que para que tenga efectos generales debe pasar por el siguiente proceso:

Artículo 107. Las controversias de que habla el artículo 103 de esta Constitución, con excepción de aquellas en materia electoral, se sujetarán a los procedimientos que determine la ley reglamentaria, de acuerdo con las bases siguientes:

Fracción II. Las sentencias que se pronuncien en los juicios de amparo sólo se ocuparán de los quejosos que lo hubieren solicitado, limitándose a ampararlos y protegerlos, si procediere, en el caso especial sobre el que verse la demanda.Cuando en los juicios de amparo indirecto en revisión se resuelva la inconstitucionalidad de una norma general por segunda ocasión consecutiva, la Suprema Corte de Justicia de la Nación lo informará a la autoridad emisora correspondiente.Cuando los órganos del Poder Judicial de la Federación establezcan jurisprudencia por reiteración en la cual se determine la inconstitucionalidad de una norma general, la Suprema Corte de Justicia de la Nación lo notificará a la autoridad emisora. Transcurrido el plazo de 90 días naturales sin que se supere el problema de inconstitucionalidad, la Suprema Corte de Justicia de la Nación emitirá, siempre que fuere aprobada por una mayoría de cuando menos ocho votos, la declaratoria general de inconstitucionalidad, en la cual se fijarán sus alcances y condiciones en los términos de la ley reglamentaria.Lo dispuesto en los dos párrafos anteriores no será aplicable a normas generales en materia tributaria. ${ }^{22}$

Por eso es importante para el juicio de derechos humanos que se genere un dinamismo procesal de presentación de casos de amparos colectivos para colmar los requisitos correspondientes y llegar a las declaratorias generales de inconstitucionalidad y generar un empoderamiento de las personas con respecto a los límites de la actividad del estado y de los particulares que ejercen funciones públicas.

Como mencioné el 4 de octubre de 2011 entró en vigor la Décima Época de la Suprema Corte de Justicia de la Nación y los criterios institucionales están definidos para su operación, se espera que con la aprobación y promulgación de la nueva de Ley Amparo en vigor, el futuro inmediato despliegue la manufactura proteccionista de este grupo de reformas.

\section{REPARACIÓN DEL DAÑO COLECTIVO}

Por último quiero mencionar que el tema de la reparación del daño cobrará en México por fin un aspecto de gran interés, es una percepción ciudadana el que la autoridad puede hacer o dejar de hace y no pasa nada, situación que debe cambiar radicalmente para establecer de poderes donde se involucre el poder ciudadano en lo individual y en lo colectivo.

\footnotetext{
${ }^{22}$ Diario Oficial de la Federación. Decreto por el cual se reforman, adicionan y derogan diversas disposiciones de los artículos 94, 103,104 y 107 de la Constitución Política de los Estados Unidos Mexicanos. México, 6 de junio de 2011.
} 
La nueva ley de amparo, desafortunadamente, no profundizó en el tema de la reparación del daño. Para los efectos de la reparación tendremos que acudir la Ley General de víctimas que ha establecido dos conceptos fundamentales y novedosos para la práctica cotidiana jurídica en México. Estos conceptos son; La reparación integral y la víctima por violaciones a derechos humanos.

La Ley General de Víctimas establece en su artículo $1^{\circ}$ :

La reparación integral comprendelas medidas de restitución, rehabilitación, compensación, satisfacción y garantías de no repetición, en sus dimensiones individual, colectiva, material, moral y simbólica. Cada una de estas medidas será implementada a favor de la víctima teniendo en cuenta la gravedad y magnitud del hecho victimizante cometido o la gravedad y magnitud de la violación de sus derechos, así como las circunstancias y características del hecho victimizante. ${ }^{23}$

Esta ley, distingue entre víctima del delito y víctima por violaciones a derechos humanos, al establecer dos supuestos de afectación. El artículo $4^{\circ}$ establece:

Se denominarán víctimas directas aquellas personas físicas que hayan sufrido algún daño o menoscabo económico, físico, mental, emocional, o en general cualquiera puesta en peligro o lesión a sus bienes jurídicos o derechos como consecuencia de la comisión de un delito o violaciones a sus derechos humanos reconocidos en la Constitución y en los Tratados Internacionales de los que el Estado Mexicano sea Parte. ${ }^{24}$

Estos dos conceptos de reparación integral y de víctima en derechos humanos, tienen su concepción relacionada a los derechos colectivos, lo cual me parece muy adecuado y por lo tanto, se confirma que la Ley General de Víctimas y la nueva Ley de Amparo estará vinculadas en los temas de derechos colectivos, aportando los elementos de reparación y reconocimiento, respectivamente. El último párrafo del artículo $4^{\circ}$ de la Ley General de Víctimas, establece:

Son víctimas los grupos, comunidades u organizaciones sociales que hubieran sido afectadas en sus derechos, intereses o bienes jurídicos colectivos como resultado de la comisión de un delito o la violación de derechos. ${ }^{25}$

Para concluir este trabajo, quiero mencionar que será un gran reto la operatividad del amparo colectivo en la Décima Época de la SCJN. Se presenta escenarios para limitar el ejercicio del poder y equilibrar la relación entre las autoridades que lo ejercen. En el Primer Aniversario de las Reformas Constitucionales de Amparo y Derechos Humanos se publicó lo siguiente por parte de la Suprema Corte de la Nación:

El Ministro Presidente de la Suprema Corte, Juan Silva Meza declaró ante la prensa, en la celebración del Primer Aniversario de la publicación de las Reformas Constitucionales en Amparo y Derechos Humanos:

El principal objetivo de los jueces es defender los derechos de las personas.Juntas, las tres reformas, significan sin exagerar la transformación del trabajo cotidiano del sistema de impartición de justicia nacional. Con puntualidad podemos hablar de una novación de nuestro sistema constitucional. Debemos celebrarlo, pues la nueva situación constitucional que nos caracteriza, es producto de un intenso esfuerzo nacional. Se impulsa por la convicción de que ahora, como nunca antes, los juzgadores debemos asumirnos como

\footnotetext{
${ }^{23}$ Diario Oficial de la Federación, Ley General de Victimas, 3 de Mayo de 2013.

${ }^{24}$ Idem.

${ }^{25}$ Idem.
} 
defensores de los derechos de las personas; más que como defensores de los intereses de la autoridad y sus políticas públicas aunque, siempre, siempre en un sano equilibrio. Por eso, nosotros los juzgadores federales, insisto, con justo equilibrio con prudente ponderación no permitiremos regresiones, que atentes contra la mejor defensa de los derechos de las personas, ese es nuestro objetivo principal. ${ }^{26}$

En el marco de esta celebración del Primer Aniversario de la publicación de las Reformas Constitucionales en Amparo y Derechos Humanos El Ministro Arturo Zaldívar Lelo de Larrea, comentó:

Concluyo diciendo que todos los jueces, particularmente nosotros en esta Suprema Corte tenemos un reto no menor, el reto de hacer en la realidad, en la vida de los mexicanos, vigente la protección y el desarrollo de los derechos humanos. Tenemos la obligación y la responsabilidad de traducir el discurso de los derechos por las sentencias de los derechos, Y cuyo propósito, es garantizar la vigencia del estado de derecho y de respeto de los derechos humanos. ${ }^{27}$

Por su parte la Ministra Olga Sánchez Cordero, al hacer comentarios en la celebración del Primer Aniversario de la publicación de las Reformas Constitucionales en Amparo y Derechos Humanos resumió:

Si yo pudiera glosar las exposiciones de mis compañeros, sería en una sola frase, hoy lo supremo son los derechos humanos por el principio pro persona. ${ }^{28}$

Sumándome a los pensamientos de los Ministros de la Suprema Corte de Justicia de la Nación, desde mi punto de vista, el gran reto es que logremos sentencias vinculantes en torno a los derechos humanos en dos ejes: la reparación del daño colectivo y el cumplimiento progresivo de los derechos humanos; sobre todo aquellos de carácter prestacional, como lo son los derechos económicos, sociales y culturales. La vinculación entre decisiones jurisdiccionales y la actividad - muchas veces omisiva - del Estado Mexicano en el cumplimiento de los derechos colectivos será decisiva para que se cumplan las expectativas de las Reformas Constitucionales de Amparo y Derechos humanos. Esta será la noble función del juicio de amparo colectivo, un icono por definir en la Décima Época de la Suprema Corte de Justicia de la Nació

\section{CONCLUSIONES}

Las tres columnas de la Reforma Constitucional de Derechos Humanos y Amparo son:

El reconocimiento de los derechos humanos establecidos en la Constitución y en los tratados internacionales firmados por el Estado Mexicano como derechos exigibles.

La posibilidad de acceder a la justicia aduciendo el interés legítimo individual o colectivo Las declaratorias generales de inconstitucionalidad, con efectos erga omnes.

Las responsabilidades y los compromisos ante la Reforma Constitucional de Derechos Humanos y Amparo son:

\footnotetext{
${ }^{26}$ Silva Meza, Juan. “ADN Noticias”. http://www.canaljudicial.wordpess.com. 23 de marzo 2013.

27 Zaldívar Lelo de Larrea, Arturo.

${ }^{28}$ Sánchez Cordero, Olga. 
Del Foro: Presentar juicios de derechos humanos en temas sensibles y de interés social.

De los Jueces: Será una ardua tarea de interpretación la que implica operar las reformas, espero que hagan valer el nuevo sistema constitucional de Derechos Humanos.

Autoridades responsables: Aplicar un nuevo ejercicio del poder, que este acotado al respeto de los derechos humanos. Este acotamiento de poder debe alcanzar a los particulares que desempeñan funciones públicas. Y en un futuro a cualquier particular que vulnere derechos humanos.

La dimensión es aún desconocida en cuanto a las repercusiones de la reforma constitucional en materia de derechos humanos y amparo, la percibo como una revolución jurídica de alcances culturales, que requiere la evolución del ciudadano considerado como una persona social.

Uno de los efectos de esta revolución jurídica - cultural, que considero como más deseable es el equilibrio de los poderes ejecutivo, legislativo y judicial con respecto a los principios de un verdadero Estado Social. Por lo pronto México con estas reformas se convierte, al menos en el papel, en un Estado Constitucional. Falta lo más importante, que México se convierta en un Estado Constitucional en la práctica diaria y que estas reformas vinculen decisiones judiciales al cumplimiento progresivo de los derechos económicos, sociales y culturales en beneficio de los más desprotegidos, reconociendo su interés legítimo en temas en los que tradicionalmente los tribunales no han ejercido su jurisdicción.

En torno al reconocimiento del interés legítimo en la nueva Ley de Amparo, mi postura es la de evitar la rigidez en la acumulación de requisitos para acreditarlo, ya que este tipo de interés no es un punto intermedio entre el interés jurídico y el interés simple. Una esfera jurídica colectiva no es la suma de esferas jurídicas individuales, ni la suma de intereses públicos subjetivos de individuos en litisconsorcio activo. Considero que en esta materia de verdad se requiere un análisis que se aparte de la clásica identificación del derecho público subjetivo de carácter individualizado y se logre una apreciación de una esfera jurídica integrada por derechos y/o intereses colectivos.

VIII. BIBLIOGRAFÍA

ABRAMOVICH, V., Courtis, C. Los Derechos Sociales como Derechos Exigibles. Trotta, Madrid 2001.

ABRAMOVICH, Víctor. Apuntes Sobre la Exigibilidad de los Derechos Sociales. Jura Gentium Revista de Filosofía del derecho internacional y de la política global. http:// www.juragentium.unifi.it 2005.

- - , Compiladores. Derechos sociales, instrucciones de uso. Fontamara, México 2005.

BENÍTEZ, A. Acciones Colectivas en México. Jurípolis Revista de Derecho y Política del Departamento de Estudios Jurídicos y Sociales de la Escuela de Humanidades y Ciencias Sociales del Tecnológico de Monterrey, Campus Ciudad de México 2009.

CANCADO, A. Derecho Internacional de los Derechos Humanos. Porrúa, México 2007.

CARBONELL, Miguel. Los Derechos Fundamentales en México. Porrúa, México 2011. 
CORCUERA, S. La incorporación y la aplicación de los tratados internacionales sobre derechos humanos en el sistema jurídico mexicano. pp. 153-170 Asociación Mexicana de Impartidores de Justicia http://www.cursosamij.org.mx/.

COURTIS, Chisthian, El Mundo Prometido, escritos sobre Derechos Sociales y Humanos. Fontamara, México 2009.

DA SILVA, V.La Interpretación Conforme a la Constitución, entre la Trivialidad y la Centralización Judicial. Cuestiones Constitucionales, Revista Mexicana deDerecho Constitucional, No. 12. UNAM. Instituto de Investigaciones Jurídicas. México 2005.

Diario Oficial de la Federación. Decreto por el cual se Modifica la denominación del Capítulo I de Título Primero y reforma diversos artículos de la Constitución Política de los Estados Unidos Mexicanos. México. 10 de junio de 2011.

- - - Decreto por el cual se Reforman, Adicionan y Derogan Diversas Disposiciones de los Artículos 94, 103,104 y 107 de la Constitución Política de los Estados Unidos Mexicanos. México. 6 de junio de 2011.

-_-. 2011. Decreto que Reforma y Adiciona el Código Federal de Procedimientos Civiles, la Ley Federal de Protección al Consumidor, de la Ley Orgánica del Poder Judicial de la Federación, de la Ley General del Equilibrio Ecológico y la Protección al Medio Ambiente y de la Ley de Protección y Defensa al Usuario de Servicios Financieros. México. 30 de agosto de 2011.

-_- Expediente Caso Rosendo Radilla Pacheco 912/2010. Pleno de la Suprema Corte de Justicia de la Nación. México 2011.

-_- Caso Radilla Pacheco. 9 de Febrero del 2010.

- - - Ley De Amparo, Reglamentaria De Los Artículos 103 Y 107 De La Constitución Política De Los Estados Unidos Mexicanos .2 de abril de 2013.

- - Ley General de Victimas. 3 de Mayo de 2013.

FERRAJOLI, Luigi. Principia Iuris. 1. Teoría del derecho. Fontamara. Madrid 2011.

GIDI Y FERRER-MACGREGOR, Antonio. Las Tutela de los Derechos Difusos, Colectivos e Individuales Homogéneos. Hacia un Código Modelo para Iberoamérica. Editorial Porrúa, México 2004.

LONDONO, M. El Principio de Legalidad y el Control de Convencionalidad de las Leyes: Confluencias y Perspectivas en el Pensamiento de la Corte Interamericana de Derechos en Humanos. Boletín Mexicano de Derecho Comparado, nueva serie, año XLIII. México. UNAM. Instituto de Investigaciones Jurídicas. México 2010.

FERRER MAC-GREGOR, E.Estudios Constitucionales. Revista Semestral del Centro de Estudios Constitucionales. Chile. Universidad de Talca, Facultad de Ciencias Jurídicas y Sociales, Centro de Estudios Constitucionales. 2006

- - Del amparo nacional al amparo internacional, Ponencia preparada para el XVII Congreso Mexicano de Derecho Procesal y VI Curso Anual de Preparación y Capacitación para Profesores de Derecho Procesal. México, 2004. 
Asociación Mexicana de Impartidores de Justicia. http://www.cursosamij.org.mx/.

GARCÍA RAMÍREZ, S. Coordinador.La jurisprudencia de la Corte Interamericana de Derechos Humanos. México, UNAM. Corte Interamericana de Derechos Humanos.2001.

MURILLO KARAM, J., Senadores de diversos Grupos Parlamentarios. Proyecto de decreto por el que se expide la Ley de Amparo reglamentaria de los artículo 103 y 107 Constitucionales y se reforman y adicionan diversas disposiciones de la Ley Orgánica del Poder Judicial de la Federación, de la Ley Reglamentaria de las Fracciones I y II del artículo 105 de la Constitución Política de los Estados Unidos Mexicanos, de la Ley Orgánica de la Administración Pública Federal, de la Ley Orgánica del Congreso General de los Estados Unidos Mexicanos, y de la Ley Orgánica de la Procuraduría General de la República. México. Cámara de Senadores del H. Congreso de la Unión. México 2011.

Organización de los Estados Americanos. Comisión Interamericana de Derechos Humano. El Acceso a la Justicia Como Garantía de los Derechos Económicos, Sociales y Culturales. Estudio de los Estándares Fijados por el Sistema Interamericano de Derechos Humanos. 2007.

PISARELLO, G. Los Derechos Sociales y sus Garantías, Elementos para una Reconstrucción. Editorial Trotta, Madrid 2007.

SCHMILL ORDOÑEZ, Ulises y DE SILVA NAVA, Carlos. El Interés Legítimo como Elemento de la Acción de Amparo. www.sitios.scjn.gob.mx/instituto/sites/ 3 marzo de 2013.

TRONT PETIT, Jean Claude. ¿Qué hay de Interés Legítimo? http://www.jeancluadetronp. com 15 de marzo de 2013.

Tribunal en Pleno de la Suprema Corte de Justicia de la Nación. Acuerdo General 9/2011, Por el que se Determina el Inicio de la Décima Época del Semanario Judicial de la Federación. Suprema Corte de Justicia de la Nación, México 2011.

ZALDÍVAR LELO DE LARREA, Arturo. Hacia una Nueva Ley de Amparo. México. UNAM, Instituto de Investigaciones Jurídicas. México 2002. 
